\title{
Problems associated with high incident beam voltage and probe current during biological x-ray microanalysis.
}

\author{
Patrick Echlin
}

\section{Cambridge Analytical Microscopy, 65 Milton Road, Cambridge CB4 1XA, United Kingdom}

X-ray microanalysis of nearly all biological specimens use a reductionist and analytic approach to combine the separate disciplines of chemistry and microscopy. Unfortunately it is necessary to use energetic electrons both to form the high resolution images and generate the emitted x-rays which are the basis of the in situ chemical identification and location. The technology is very invasive, particularly for biological samples which are poor electrical conductors, radiation sensitive and full of water. The improvements in specimen preparation and the algorithms used for analysis, now make it possible to measure very low concentrations of light elements at better than $10 \mathrm{~nm}$ spatial resolution. This paper will consider ways to diminish the damage which high voltages and probe currents cause during sample examination and microanalysis.

Plant, animal and microbial samples have a very low electrical conductivity. For example, the conduction of silver and the noble metals are $10^{9}$ times higher than either bone or wood. Biological materials invariably exhibit charging phenomena when irradiated with an electron beam. Charging effects the specimen in many ways. (1) It will cause changes in the primary beam landing energy, decrease the electron penetration depth, alter the spatial location of emitted x-rays and severely distort the appearance of the secondary electron image. Charge elimination may be achieved either by noninvasive procedures which make minor alterations to the microscope or invasive procedures which can severely alter the specimen.

Charge elimination is readily achieved by lowering the incident beam voltage and probe current to ensure that minimum energy is used to obtain the maximum information about the specimen. Every sample has it unique set of values which may be easily determined. Much is now understood about the general features, and advantages of low voltage scanning electron microscopy. The recent papers by Boyes (2) and Joy (3) show that voltages as low as $20 \mathrm{eV}$ can be used to obtain images in the scanning electron microscope. The minimum voltage needed to ensure quantitative $\mathrm{x}$-ray biological microanalysis is 15 to 100 times higher. However, low voltage operation has additional advantages.

For all samples, there is a marked decrease in the size of the sample-beam interactive volume as the specimen density increases and the incident beam voltage decreases. One way around this apparent paradox is to only use a thin flat section of the biological material to ensure that a substantial part of the energy of the incoming electron beam passes through the specimen without scattering. Unfortunately, all sectioning procedures are invasive. Low temperature procedures have the least effect (4) while the use of chemicals will readily lead, either to translocation or complete loss of the elements. An alternative way to reveal the interior of a sample is to either make an impact fracture or microplan a broken surface with a sharp knife. Both processes produce a bulk sample with a clean, relatively smooth, surface. If the empirical formula of the specimen is known, the dimensions of the samplebeam interactive volume can be measured by using one of the different range equations. An example now follows.

Frozen hydrated tea plant epidermal cell wall are considered to have the following composition. Water (ice) $60 \% \delta=978 \mathrm{~kg} / \mathrm{m}^{3}$, structural carbohydrates $34 \% \delta=300 \mathrm{~kg} / \mathrm{m}^{3}$, protein $3 \% \delta=1200 \mathrm{kgm}^{3}$, and the principle combined elements $\mathrm{Mg}, \mathrm{Al}, \mathrm{Si}$ and $\mathrm{Ca} 3 \% \delta=1800 \mathrm{~kg} / \mathrm{m}^{3}$. The weight average density of the frozen hydrated material at $150 \mathrm{~K}$ is $780 \mathrm{~kg} / \mathrm{m}^{3}$. Using the Bethe Range equation $\mathrm{Rb}=70(\mathrm{E} 1.66 / \delta)$ where $\mathrm{Rb}$ is the penetration depth in $\mu \mathrm{m}, \mathrm{E}$ is the incident beam energy in $\mathrm{KeV}$ and $\delta$ the density, the dimension of the interactive volume may be readily calculated for different beam voltages. For this particular specimen, the interactive volume is $18 \mu \mathrm{m}^{3}$ at $10 \mathrm{kV}, 0.6 \mu \mathrm{m}^{3}$ at $5 \mathrm{kV}$ and $0.006 \mu \mathrm{m}^{3}$ at $2 \mathrm{kV}$ and there is a $9 \times 10^{4}$ decrease in the dimensions of the interactive volume between 10 and $1 \mathrm{kV}$. The 
diminished interactive volumes associated with reduced voltages, have to be balanced against the higher energies needed to generate sufficient x-ray in the sample in order to carry out quantitative analysis. For the type of sample discussed above, this may be achieved at $1.0 \mathrm{keV}$ for $\mathrm{C}, \mathrm{N}$ and $\mathrm{O}$, at $2-3 \mathrm{keV}$ for $\mathrm{Na}, \mathrm{Mg}, \mathrm{Al}$ and $\mathrm{Si}$, and at $4-5 \mathrm{keV}$ for $\mathrm{P}, \mathrm{S}$ and $\mathrm{Cl}$. It has been found necessary to go to $8 \mathrm{keV}$ for $\mathrm{K}$ and $\mathrm{Ca}$. It remains to be seen whether it will be possible to analyse $\mathrm{K}$ and $\mathrm{Ca}$ at $1.0 \mathrm{keV}$ by using the $\mathrm{L}$ lines for these two elements at 0.259 and $0.341 \mathrm{keV}$, respectively. Before undertaking any quantitative biological microanalysis it is important to first establish the minimum voltage and beam current which will give the smallest sample interactive volume while at the same time generating sufficient X-rays.

The charging of non-conductors is readily overcome by coating the specimen with a very thin layer $(2-3 \mathrm{~nm})$ of a conductive material which must not contribute to the x-ray spectrum of the specimen being analysed. Tables 1 and 2 give an outline of some of the properties of seven materials which may be used.

Table 1. Physico-chemical properties of seven elements which may be used for coating for the $\mathrm{x}$-ray microanalysis of non-conducting biological samples. $\mathrm{Ev}=$ evaporation, $\mathrm{Sp}=$ sputtering.

\begin{tabular}{lccccccc}
\hline & $\mathrm{Be}$ & $\mathrm{C}$ & $\mathrm{Al}$ & $\mathrm{Cr}$ & $\mathrm{Ti}$ & $\mathrm{V}$ & $\mathrm{Pd}$ \\
\hline Density $\left(\mathrm{Kgm}^{3)}\right.$ & 1800 & 2300 & 2700 & 7200 & 4500 & 6100 & 12024 \\
Conduction $(\mathrm{W} . \mathrm{cm})$ & 2.00 & 1.29 & 2.37 & 0.93 & 1.74 & 0.31 & 0.72 \\
Resitivity $(\mu \mathrm{ohm} . \mathrm{cm})$ & 4.27 & 3500 & 2.83 & 13.0 & 5.50 & 18.2 & 10.0 \\
Evaporation $\left(0^{\mathrm{c}}\right)$ & 1247 & 2727 & 1002 & 1177 & 1819 & 2161 & 2363 \\
Coating method $(\mathrm{Sp} / \mathrm{Ev})$ & $\mathrm{Sp}$ & $\mathrm{Ev}$ & $\mathrm{Sp} / \mathrm{Ev}$ & $\mathrm{Sp} / \mathrm{Ev}$ & $\mathrm{Sp} / \mathrm{Ev}$ & $\mathrm{Ev}$ & $\mathrm{Sp} / \mathrm{Ev}$ \\
K series x-ray $(\mathrm{KeV})$ & 0.110 & 0.282 & 1.487 & - & - & - & - \\
L series x-ray $(\mathrm{KeV})$ & - & - & - & 0.571 & 0.452 & 0.510 & 2.838 \\
\hline
\end{tabular}

Table 2. Possible interference between the x-ray lines of coating materials and biological light elements $(Z=6-20)$ using an energy dispersive spectrometer with a resolution of $130 \mathrm{eV}$.

\begin{tabular}{ll}
\hline \multicolumn{1}{c}{ Element used for coating } & \multicolumn{1}{c}{ Elements which will suffer interference } \\
\hline Beryllium $\mathrm{K} \alpha_{1}$ line $=0.110 \mathrm{Kev}$. & No interference \\
Carbon $\mathrm{K} \alpha_{1}$ line $=0.282 \mathrm{Kev}$. & Interference with $\mathrm{K}-\mathrm{L} \alpha_{1}(0.259)$ and $\mathrm{Ca}-\mathrm{L} \alpha_{1}(0.341)$ \\
Aluminium $\mathrm{K} \alpha_{1}$ line $=1 . .487 \mathrm{Kev}$ & Interference with $\mathrm{Mg}-\mathrm{K} \alpha_{1}(1.254)$ and $\mathrm{Si}-\mathrm{K} \alpha_{1}(1.740)$ \\
Titanium $\mathrm{L} \alpha_{1}$ line $=0.452 \mathrm{KeV}$ & Interference with $\mathrm{N}-\mathrm{K} \alpha_{1}(0.392)$ and $\mathrm{O}-\mathrm{K} \alpha_{1}(0.525)$ \\
Vanadium $\mathrm{L} \alpha_{1}$ line $=0.511 \mathrm{Kev}$ & Interference with $\mathrm{O}-\mathrm{K} \alpha_{1}(0.525)$ \\
Chromium $\mathrm{L} \alpha_{1}$ line $=0.571 \mathrm{KeV}$ & Interference with $\mathrm{O}-\mathrm{K} \alpha_{1}(0.525)$ \\
Palladium $\mathrm{L} \alpha_{1}$ line $=2.838 \mathrm{KeV}$ & Interference with $\mathrm{Cl}-\mathrm{K} \alpha_{1}(2.622)$ \\
\hline
\end{tabular}

All seven elements indicated above have both advantages and disadvantages and it is unlikely that a single element will provide an ideal material for all the elements of interest in the particular biological material being analysed. If it is necessary to apply a coating layer prior to carrying out $\mathrm{x}$-ray microanalysis, it is important to first check whether any adverse interrelationships may exist between the elements being analysed and the elements being considered as a coating material.

\section{References}

1. J. I. Goldstein et al. Scanning Electron Microscopy and X-ray Microanalysis $3^{\text {rd }}$ Ed.

Klewer/Plenum. New York, (2003)

2. E.D. Boyes. Micros. Microanal, 8 (Suppl, 2) (2002), 122.

3. D. C. Joy. Proceedings Vol 3. $15^{\text {th }}$ Int. Conf. Electron Microscopy, Durban. (2002) 93

4. P. Echlin. Low Temperature Microscopy and Analysis. Plenum. New York (1992) 